\title{
Urban Policy Observatory Programme for Sustainable Cities and Communities Mapping in Poland
}

\author{
Dariusz Dukaczewski $^{\text {a, }}$ * Anna Markowska ${ }^{\text {b, }}$ \\ ${ }^{a}$ IGiK - Institute of Geodesy and Cartography, 27 Modzelewskiego St.02-679 Warsaw, Poland, dariusz.dukaczewski@igik.edu.pl \\ b IGiK - Institute of Geodesy and Cartography, 27 Modzelewskiego St.02-679 Warsaw, Poland, anna.markowska@igik.edu.pl \\ * Corresponding author
}

Keywords: EO data, SDG Indicators, SDG Dasymetric Indicators, Geospatial Analysis, Sustainable Cities Mapping

\section{Abstract:}

The set up of the Sustainable Development Goals (SDGs) included in a UN Resolution 'Transforming our world: the 2030 Agenda for Sustainable Development' (United Nations, 2015), as well as adoption of the list of global indicators (United Nations, 2017; United Nations Statistics Division, 2020) resulted in growth of interest of national statistical offices in formulation of the national SDG indicators. In the case of SDG 11 goal 'Make cities and human settlements inclusive, safe, resilient, and sustainable', especially targets 11.3 (Inclusive and sustainable urbanization), 11.6 (Reduce the environmental impacts of cities) and 11.7 (Universal access to safe, inclusive and accessible, green and public spaces, particularly for women and children), the special attention was focused on Earth Observation (EO) data. There are no doubts, that employment of Earth Observation indicators can provide the up-to-date, continuous, homogenous, harmonized and repeatable information for production of SDG 11 statistical indicators. This kind of information is of the greatest economic significance for public administration of central, regional and local level, as well as for citizens. It should be stressed, that Polish national statistics office - Statistics Poland (GUS) gathers a part of the information, which can be useful to generate 11.3, 11.6 and 11.7 indicators, but these data (based on terrain survey and point monitoring) are related to the administrative units only and are not continuous, neither harmonized. This data only partially meet the recent needs of public administration. GUS and public administration in Poland are vitally interested to produce up-to-date, dasymetric SDG 11.3, 11.6 and 11.7. indicators related to the existing topography, employing EO data. To achieve this goal we have started the Urban Policy Observatory Project carried out by the consortium of IGiK (Institute of Geodesy and Cartography - leading Polish institute responsible for research on cartography, geodesy, photogrammetry (since 1945), geoinformation / geomatics (1962), satellite remote sensing (since 1974) and advanced spatio-temporal Earth science analyses, Statistics Poland (GUS) - Poland's central office of government administration charged with collecting, analysing and publishing statistics, Urban Policy Observatory of Institute of Urban and Regional Development - IRMIR, The Office of the Marshal of the Mazowieckie Voivodeship (the biggest administrative unit in Poland - the area of $35558,47 \mathrm{~km}^{2}$ and $5,39 \mathrm{mln}$ inhabitants), as well as the Faculty of Geography and Regional Studies of the University of Warsaw. The goal of this project is to elaborate, test and publish (in a form of official statistical specification) the operational methodology of production of new dasymetric SDG 11.3, 11.6 and 11.6 indicators, based on EO data (especially combination of remote sensing indexes) and in-situ data.

In the research reported here, we have proposed the methodology of production of dasymetric SDG 11.3, 11.6 and 11.6 indicators, based on EO data and in-situ data, adjusted to the possibilities and needs of Statistics Poland and Polish public administration (https://eo-toolkit-guo-un-habitat.opendata.arcgis.com/pages/poland-use-case). The Target 11.3 indicators will be based mainly on Sentinel-2 EO data. However, according to the results of carried tests in the case of 4. 7\% of territory of Poland it is advisable to use the satellite data of bigger resolution (WorldView-3 and -4). Both EO data will be classified employing Random Forest Boosted algorithm and Super Vector Machines learning models. The resulting detailed land use map will be object of geospatial analysis, employing CORINE Land Cover level 3 database and Urban Atlas database of Poland, as well as topographical database BDOT10K of level of details corresponding to the maps of 1: 10000 scale, available up-to-date orthophotomaps and EGiB Lands and Building Records databases. The result will be CORINE Land Cover level 6 database for areas of cities. EO data will be also employed to produce EO Urban Indices (e.g. NDVI, SAVI, BI, IB, TSAVI, CI, XVI and RI). The statistical urban data and CORINE Land Cover level 6 database will be employed to elaborate the Population Density Dasymetric Map, showing the density of the population related to the urban land use classes polygons This way it will be possible to have detailed information about the internal diversity of density of urban population of definite level of reliability (E. Bielecka, D. Dukaczewski, 2006). The geospatial analysis of EO Urban Indices, the CORINE Land Cover level 6 database and multitemporal analysis of principal components will allow calculating the Urban Indices (Modified SDG Indicator 11.3.1.d Dasymetric sustainable urbanization rates, Dasymetric Indicator of Urban Density, Dasymetric Indicator of areas in urban conversion process, Dasymetric Indicator of abandoned arable land and Dasymetric Indicator of build-up areas on landslide risk zones) in a form of maps, which together with the Population density Dasymetric Map will allow to prepare analytical dasymetric maps for support of sustainable human settlement monitoring and planning. It will be also possible to calculate the 'standard' SDG Indicator 11.3.1 - Sustainable urbanization rates. Statistics of the Head Office 
of Geodesy and Cartography will allow also to calculate the SDG Indicator 11.3.2 - Urban planning management. The proposition of introduction of additional Modified SDG Indicator 11.3.1.d - Dasymetric sustainable urbanization rates (ratio of land consumption rate to population growth rate referred to topographic polygons of different types of urban land use/land cover and different groups of the population) can solve the problem of heterogeneity of urban areas (including some non-urban land types), mentioned by R. Nicolau et al. (2019).

The proposed methodology of production of Target 11.6 SDG dasymetric indicators employs also the procedure of production of CORINE Land Cover level 6 land use map. The EO Urban Indices are needed together with statistical data to prepare the population density dasymetric map and urban indices dasymetric maps. These maps allow to prepare Modified SDG Indicator 11.6.2.d - Dasymetric indicator of urban air pollution (annual mean levels of a fine particulate matter referred to topographic polygons of different types of urban land use/land cover and different groups of the population). Geospatial analysis of maps of air pollution, maps of noise and maps of traffic allows to prepare maps of traffic pollution, maps of non-traffic pollution and maps of traffic noise. These maps, together with the dasymetric map of pollution in urbanized areas allow establishing the analytical dasymetric map of pollution in urbanized areas. Geospatial analysis of day and night aeration corridors, as well as meteorological maps and meteorological satellite data, allow elaborating the map of the state of pollution and aeration. The result of the analysis of this map, as well as aggregated medical statistics and maps of air pollution, will be a dasymetric map of city aeration system deficit.

The CORINE Land Cover level 6 land use map will be also employed in proposed method of production of Target 11.7. SDG dasymetric indicators. This database will be a source material for elaboration of harmonized maps of lands allocated to streets, map of built areas, map of public urban facilities, map of open public space, map of potential open public space, as well as a map of green public areas. The EO urban data and EO indices are needed together with statistical data to prepare the age, gender, disabilities population density dasymetric map and urban indices dasymetric maps. These data are necessary to calculate the SDG Indicator 11.7.1 and Modified SDG Indicator 11.7.1.d. Employing maps of lands allocated to streets, maps of built areas, maps of public urban facilities, maps of open public space, maps of potential open public space, maps of green public areas, as well as maps of blind and eye impaired paths, maps of urban accessibility together with age, gender, disabilities population density dasymetric map and urban indices dasymetric map it is possible to elaborate analytical dasymetric map of types of urban open public spaces and its accessability. This map can be used (together with a map of noise, a map of pollution, a map of traffic accidents, a map of crimes and offences and a map of barriers to calculate the SDG Indicator 11.7.2 'Safe spaces in cities', modified SDG Indicator 11.7.2.d 'Dasymetric Indicator of open spaces in cities and its accessability', as well as to prepare the analytical map of types of urban safe open public spaces, its accessibility and barriers. In the case of Upper Silesia Coal Region Conurbation, the additional analysis of stability of surface (based on Radar EO interferometrical data TerraSar$\mathrm{X})$ can be carried out. The surface stability is a very significant problem in this region due to mining activities. It affects both residential buildings and public infrastructure and it has a strong impact on citizens' sense of security.

The proposed methodology of production of SDG 11.3, 11.6 and 11.7 dasymetric indicators, taking into consideration the specificity of in-situ data, is adapted for usage in Poland. However, it should be stressed that it is possible to take also into consideration the data from other CORINE Land Cover level 5 or 6 databases and other national topographic and/or thematic databases. This can allow to use the proposed method of production of SDG dasymetric indicators also in other countries.

Bielecka E., Dukaczewski D. (2006): Problemy redakcji mapy dazymetrycznej gęstości zaludnienia. Ocena porównawcza odbioru kartogramu dazymetrycznego wykonanego różnymi metodami, XV Szkoła Kartograficzna Książ, Książ, 25 - 27. 04. 2006, [ed.] W. Pawlak, W. Spallek, Uniwersytet Wrocławski, Wrocław, p. 89 - 102, ISBN 83-915878-7-8

Nicolau R., David J., Caetano M., Pereira J. M. C, (2019) Ratio of Land Consumption Rate to Population Growth Rate - Analysis of Different Formulation Applied to Mainland Portugal, International Journal of Geo-Information, 8(1), 10; https://doi.org/10.3390/ijgi8010010

United Nations (2015) Resolution adopted by the General Assembly on 25 September 2015, Transforming our world: the 2030 Agenda for Sustainable Development (A/RES/70/1)

United Nations (2017) Resolution adopted by the General Assembly on 6 July 2017, Work of the Statistical Commission pertaining to the 2030 Agenda for Sustainable Development (A/RES/71/313)

United Nations Statistics Division - UNSD (2020) SDG Indicators - Global indicator framework for the Sustainable Development Goals and targets of the 2030 Agenda for Sustainable Development 